\title{
The Many Contexts of the Social RESPONSIBILITIES OF UNIVERSITIES
}

\section{Colin Brock ${ }^{\dagger}$}

Zhou Zhong

Tsinghua University

\begin{abstract}
It has long been established that universities have three main functions: to teach, to research and supervise research, and to benefit the communities and regions in which they are located. In reality, the third main function permeates the other two. There are clearly social responsibilities to the students and to the staff who teach them and/or maintain their well-being through administration and other services such as counselling. Including issues of physical, social and economic well-being in their research portfolios is also common, though not universal. In this paper, we take a spatial scale approach to social responsibilities, which can take us from social responsibilities within the university, through what might be termed 'civic responsibilities', on to the immediate populations of a town or city, and then to 'regional and international responsibilities'. The impact of the COVID19 pandemic in line with the sector's social responsibility dynamic is also examined.
\end{abstract}

Keywords: University Social Responsibility; Education for Sustainable Development; Spatial Approach to Social Responsibility

\section{Introduction}

It has long been established that universities have three main functions: to teach, to research and supervise research, and to benefit the communities and regions in which they are located (Boyer, 1996). In recent times, in the context of near-global neo-liberalism, a fourth may have been added: to make money (Kasperkevic, 2014). Private universities, being by definition businesses, have always had this function as an institutional necessity, but there are concerns in the United Kingdom (UK) hat new private providers are emerging, with some government encouragement, that are seeking the title 'university' but which are in fact lacking the social and intellectual dimensions of such institutions that traditionally hold that title.

In reality, the third main function permeates the other two. There are clearly social responsibilities to the students and to the staff who teach them and/or maintain their well-being through administration and other services such as counselling. Including issues of physical, social and economic well-being in their research portfolios is also common, though not universal. Some highly respected institutions of higher education are, by definition 'institutes of technology' in which few, if any, issues of the well-being of humanity may exist in their academic activities. Whether such institutions should be regarded as 'universities' is a moot point and beyond the scope of this paper, but they would have similar social responsibilities outside of the academic sphere.

Nicholas Maxwell, in his important letter to The Guardian newspaper of October 2013, in effect places the social responsibility of universities at the core of their raison d'etre: 
Of course universities should invest in the future (Letters $25^{\text {th }}$ October). The problem is they don't. Climate change, population growth, mass extinctions and other global problems mean that we are heading towards disaster. If we are to make progress towards as good a better world as possible - or at least avoid the worst of disasters - we need to learn how to do it. That in turn requires that our institutions of learning are rationally designed and devoted to the task.

This implies a social responsibility of universities on a global scale and connects with what James Martin (2006) termed 'the skills-wisdom gap'. He was referring to the increasing danger for humankind of technological expertise outreaching the ability of governments, and people in general, to control and direct it to peaceful and constructive objectives. One such example would be the capacity of humans to cope with the ever-decreasing scale of nanotechnologies involved in everyday life. Of the seventeen existential issues ranged by Martin (2006), he saw the closing of the skills-wisdom gap to be a role for elite universities. To this end, he founded The Oxford Martin School in 2005, which, though based in Oxford, has over 200 associated researchers worldwide and supports the work of others provided that:

(...) to qualify for our support, the research must: be of the highest academic calibre; tackle issues on a global scale; could not have been undertaken without our support; and have a real impact beyond academia (Oxford Martin School Website).

This global initiative of social responsibility is paralleled by the Cambridge Centre for the Study of Existential Risk, founded in 2011 by Martin Rees, former Astronomer Royal and Master of Trinity College. It has somewhat of a focus on ICT and economics (Brock, 2016).

The efforts of Maxwell, Martin and Rees are examples of universities exercising their social responsibilities on a grand, indeed global, scale. Spatial scale is one way of recognising the range of social responsibilities of universities. It is one dimension of context, what the Centre for Educational Research and Innovation (CERI) of the Organization for Economic Co-operation and Development (OECD) termed: 'a geographical, institutional and administrative approach'. Such an approach has now been overtaken by the advances in Information Communications Technology (ICT) that have long since liberated the geographical from the political, though to different degrees in the range of countries and regions. ICT has enabled innumerable pathways of influence, included those of social responsibilities, to escape the bounds of regulated spaces of various scales.

Nonetheless, in broad terms, we may accept the spatial scale approach to social responsibilities, which can take us from social responsibilities within the university, through what might be termed 'civic responsibilities', on to the immediate populations of a town or city, and then to 'regional responsibilities'. This means the contiguous region or sphere of influence of the town or city within which the university resides. Beyond that lies the nation (or in some cases autonomous regions within it) and any multinational grouping to which that nation might belong, such as The European Union (EU) or The Association of South-East Asian Nations (ASEAN). Sometimes there may be multiple regional responsibilities such as, in addition to the EU, the Council of Europe and The European Educational Area. For example, the Bologna Process, which has no spatial limit, has within its rationale an element of social responsibility towards the populations within its terms of their tertiary educational entitlements and mutual recognition. In addition, there is the phenomenon of 'education hubs', which are independent and dynamic, but which still have social responsibilities.

\section{Social Responsibilities within the University}

This can begin before students arrive at the university. Most undergraduates have little understanding of the ambience of a university before they arrive there. Increasingly universities in the UK are organising 'open days' or other access experiences. These are invaluable, especially, as with the exception of some elite institutions, selection interviews are now uncommon. Hopkins (2006) 
examined the LEAPS programme in Scotland (The Lothians Equal Access Programme for Schools), which has been in operation since 1995. This might also be regarded as an aspect of social responsibility to the community, but for this particular potential clientele is a matter of transition from one to the other. LEAPS participants were attentive to issues within the university that they hoped would be a transition rather than a break; issues such as "money, finance, exams, drinking, clubbing and socialising" ( $p$ 246), and the social class make - up of the institution, avoiding institutions popular with a 'rich upper-class elite' (ibid.).

Once at university, two main areas of social concern to students are provision for those with disabilities and a sophisticated understanding of the concerns and needs of social and cultural minorities. There can be an overlap between these two. For example, Horton and Tucker (2014) ask: "are spaces of academia conducive to poor public health?" ( $p$ 76). They surveyed students and staff mostly in the UK, but also in Canada, finding evidence of both having to hide their problems due to their institutions being somewhat unforgiving. Once 'outed', so to speak, such individuals and minorities tended to take the lead in questioning the shortcomings of their universities in respect of minority issues. One such group is Muslim students, as examined by Hopkins (2011), on a campus some way out of the city context in the UK. In general, responses were quite positive, mainly on the grounds that the campus population is necessarily more educated than the general public in the areas they have come from. Nonetheless, the inevitable penetration of the campus by national and social media followed them with negative reactions, which the university should try to alleviate as far as possible. There were issues such as the Mosque often being in a peripheral location, which had some kind of message and posed dangers for female students, especially. Also, whereas every college or hall had a bar (or pub as they called it), coffee bars and other such facilities were not so regularly available. In general, however, universities are reckoned to be 'enabling environments' (Swain et al., 1993), where students and staff with any kind of minority issue or condition can form spaces for themselves. Johnson and Castleden (2011) report on an example of involving students in the design of a campus, praising "the desirability of student-based involvement in the evaluation and mapping of future land development on the campus" (p 353).

The provision of residential facilities for students is another important social responsibility for universities. It varies as between countries where living away from home is seen to be part of the university experience. This is somewhat different between England and Scotland, wherein the latter studying at the local university and living at home is longstanding. In England, the collegiate tradition of Oxford and Cambridge, followed by Durham, has been an influence, though the increase in student numbers means that few undergraduates in the two ancient universities are fortunate to get more than one year in college residence. Durham City is very small, so the university still maintains a tradition of offering most undergraduates there years in college residence. A few modern universities, such as Kent and York, are collegiate. Most universities, however, have developed halls of residence for those students who opt for in-house accommodation. Others prefer or may have to seek residence in the private sector, but even here, universities have a duty to monitor the schemes and organisations that offer it.

Beyond the particular issue of residential responsibility is that of the wider wellbeing of students. Fleuret and Prugneau (2015) build on and adapt the theoretical framework of Fleuret and Atkinson (2007), which looks at student wellbeing from a spatial view and suggests four dimensions of space in the university setting that are relevant: spaces of a) security, b) capability, c) therapeutic and d) integrative. With respect to their study of these issues in relation to the University of Angers, France, they conclude:

The results reveal that the student population has a specific relation to space due to a transitory presence in the university town, with, as a consequence, a simultaneous embedding in different places. This could explain why the students do not perceive the characteristics of place to be a major influence on their wellbeing; instead it is the perception they have of their well-being that influences their perception of place (Fleuret \& Prugneau, 2015, p 110). 
One may infer from this that how a university cares for the wellbeing of its students has, at least to some extent, to do with how it lays out the locations of academic facilities in relation to its social and residential facilities. Angers is referred to as 'a university town', with its faculties centred in three areas and sports facilities in another.

The idea of a university town in itself seems to infer some kind of social responsibility. In such places, universities can have a very significant multiplier effect. This is an economic concept but not entirely unconnected with the social. In attempting to respond to the UK government cuts in university funding and capacity in the early 1980s, it transpired that the University of Hull was the second largest employer in a city of over 250,000 people. This does not directly mean that the university had a social responsibility to the city and its people, but it did illustrate a considerable and intimate economic and social relationship between the university and the community.

\section{The University and the Community}

With the exception of universities in so-called greenfield sites, most, at least in the UK, are in towns or cities. There may be more than one, as in Birmingham, Bristol and Leicester, and of course, London. In the case of Manchester, there were several that have now coalesced into one. They vary according to the degree to which their foundation corresponds to the development of the city concerned. In the case of the so-called 'redbrick' universities associated with nineteenth and early twentieth-century urbanisation in England, they range from colleges founded to help address the severe health and engineering issues of industrialisation to a kind of civic status recognition. That is to say, from Owens College, Manchester in 1840 to University College, Hull in 1927. Indeed, both had antecedents with distinct civic objectives in the form of the Manchester Mechanics Institute (1824) and the Hull University Extension Society (1876), the latter being founded by a small group of businessmen in association with the University of Cambridge adult education extension services. During the 51 years leading to the foundation of University College, Hull, the Hull University Extension Society "fitted into the matrix of voluntary organisations in Hull, and, given the apathy of the Corporation to its responsibilities in this field, alone provided the basis of higher education in the later nineteenth century" (Bamford, 1978, p2). Such responsibilities were also the interest and role of the Oxford Delegacy, "an organisation dedicated to bringing educational opportunities to adults in many locations throughout the country" (Brock \& Alexiadou, 2013, pp 9-10). Michael Sadler, later to become the founding father of comparative education, was appointed Secretary to the Oxford Delegacy in 1885, and in 1891 co-authored with Halford Mackinder, Professor of Geography at Oxford: University Extension, Past Present and Future. Given that the universities of Oxford and Cambridge were engaged in adult extension activities prior to the beginnings of state education for all at the primary level in 1870, that is an interesting commentary on the social responsibilities of universities in itself. But it is with the aforementioned so-called civic foundations from Manchester onwards that the scale of interest could be called one of community. As far as England is concerned, such universities were part and parcel of a rapidly growing and new kind of community, the city. To what extent the term civic university can reasonably be applied to them is one of the considerations.

Nonetheless, there is a significant place and function in the university to go beyond the early work of adult extension education mentioned above to a wider engagement with the town or city in which it is located. That of being an employment multiplier, beyond that of academic staff, has already been mentioned. The Council, or governing body, of most universities in England, is largely made up of local leaders of industry, commerce, politics and religion. Among other things, they appoint the Vice-Chancellor, the leader of the university, who then also becomes a local figurehead also involved in various aspects of civic life. In some cities, new universities have developed, often from well-established local technical colleges and polytechnics, which already have community connections and in some cases may develop more of a contemporary social responsibility function than the older university foundation itself. This may be seen in Bristol, Birmingham, Oxford and Cambridge. 
Universities in all four constituent parts of the UK engage in a range of initiatives that are of benefit to their local communities, from primary schooling to social welfare. For example, Swain (2016) reports on universities involving themselves in establishing and supporting 'free schools' and 'university technical colleges'. On the free schools' issue the Vice-Chancellor of Birmingham University is quoted as stating that "sponsoring a free school is part of a 'civic duty"' (ibid. p36). But this view is challenged by Nadia Edmond in the same publication: "They talk a lot about partnership with the community but it's undermining those partnerships because it is privileging particular relationships with particular schools and not others" (ibid). Where university technical colleges are concerned, these are less contentious. They aim to be a bridge between school and university in towns that are within the wider sphere of influence of a city but somewhat on the periphery. The university colleges promoted by the University of Hull, for example, are located in Grimsby and Scarborough.

Within the immediate, wider and more peripheral sphere of influence of a town or city, universities engage in a wide range of social and economic activities. Notable in researching and indeed supporting such activities is the well-established Centre for Urban and Regional Development Studies (CURDS) at the University of Newcastle, established in 1977. Since then, it has generated over 30million British Pound Sterling (GBP) of research activity, including on local and regional cultures and identities through the UK. Among the 2016 research and development programmes of Curds are: a) The Civic University Study Programme (CUSP), Creativity, Culture and Education in Schools and Civic Universities, and Social Inclusion through the Digital Economy (SIDE). These are clearly seen as part of the social responsibility of the university.

\section{Universities and the International Community}

Universities have, almost by definition, long been seen to be international institutions. International staff and student migration generate and serve clear social responsibilities. (Findlay et al., 2012), argue with respect to UK students enrolled in six overseas institutions that significant social and cultural capital accrues from such experiences. The international hierarchy of universities in the form of a global league table was seen as a determining factor in choice of destinations, but the criteria on which the tables are based have little to do with social responsibilities of such institutions. Yet, as the writer has argued (Brock 2012, p.49), internationalism as opposed to internationalisation:

....has its roots in the free association of scholars that predates the establishment of nation states with their frontiers securing a regulated space. As such internationalism is a fundamental feature of an ideal university, one that signifies its integrity

In these terms, it could be seen as a social responsibility, especially in the face of the potential and likely imminent social and environmental catastrophes predicted by Martin (2006) and Maxwell (2013) that predicate this discussion. Through their high level of skills in ICT, universities can operate simultaneously at global and local levels. In the latter context, a university, or in less developed communities, some other post-secondary institution, could lead and contribute towards educational and social innovation "to enable the community to come to terms with its environmental challenges both physical and socio-cultural” (ibid. p 60). In so doing, in Martin's (2006) terms, universities would be serving their function of social responsibility through a new type of thinking about the future by reflecting on what might now be possible in particular localities and regions.

But universities are in general related to cities, and as the world of education has become globalised, so those cities that are expanding have become nodes of global information and knowledge networks. This goes beyond the political, social and cultural activities of their respective locations and communities, and indeed beyond the countries in which they are located. It has even been suggested that such city nodes are the 'new countries', freed from national political regulated space, 'spaces of identity' (Morley \& Robins, 1995). Such spaces can influence and change the spatial and social morphology of cities, as in Buenos Aires (Ciccolella \& Mignaguil, 2002) and Amsterdam 
(Riemens \& Lovink, 2002).The numerous international networks of ICT that now exist and overlap sometimes have nodes that are, in effect, 'education hubs'. Some such hubs have been developed by commercial and/or national policy and are sufficiently numerous to suggest a typology of education hubs (see Symaco \& Brock, 2016)

Transnationalism has become a common feature of the universities in "the thickening of interdependence" (Keohane \& Nye 2000, p. 21). Transnationalism generally refers to a multilayered process of expanding and accelerating activities and impact across national borders. As the 'multiversity' (Kerr 2001, p. 1-34) and the 'city of the intellect' (Kerr 2001, p. 64-95), the universities, especially those with intensive research, serve as both localised nodes and global hubs of networks in educational, socioeconomic, political and cultural processes stretching over many spatial scales. The outbreak of the COVID-19 pandemic in 2020 caused unprecedented disruption to the education sector (UNESCO, 2020). Amid the public crisis gloom, universities worldwide serve as a lighthouse to sustain an array of academic and social responsibilities: innovating online and hybrid education to its students and the public, research in vaccine and other pandemic coping solutions while maintaining safety and health on campus. There is also the provision of advice to the government and counselling to the general public, creating an ethos of resilience and mutual support in society.

In the COVID-19 pandemic context, the pandemic's 'physical distancing' resulted in a dislocated and disparate university communities across the world. Many universities took their first emergency response to go virtual and collaborated with domestic and overseas universities and organisations for humanitarian efforts. The students and staff became 'digital transmigrants' (Schiller, Basch \& Blanc 1995, p. 121). They maintained multiple and constant digital interconnections across physical or social borders, and their public identities were re-configured about several 'territorial spaces'. In this context, universities were re-spatialized across physical and virtual spaces (through a network of networks or a process of networking). As pointed out by Brock (2016, p.168), the basic spatial issues in such context are that of "(a) access to the digital dimension of education provision; (b) the nature and quality of that provision and (c) technical ability to interpret and manipulate it, are all extremely disparate in spatial and location terms."

Such efforts were diverse and distributed but also often transactional and fragmented. Disparities generated a more prominent 'digital divide' in terms of differences in digital skills and infrastructure and social-emotional well-being. Many students and scholars found themselves unable to function well without the ambience of a close-knit, well-served, and often highly-regulated timespace of a physical campus or even a classroom. The higher education sector has taken the social responsibility to tackle such a digital divide in its community. A key issue is to harness technology to make the university more open and integrative and promote a more resilient and responsive institution.

\section{The University for Sustainable Development (USD)}

In today's world full of volatility, uncertainty, complexity and ambiguity, survival depends on innovative learning-based solutions through collaborations. The university's social responsibility has increasingly integrated into the notion of the University for Sustainable Development (USD) or Education for Sustainable Development (ESD). A major ESD landmark is the Talloires Declaration (1990) for 'incorporating sustainability and environmental literacy in teaching, research, operations and outreach at colleges and universities'. Initially signed by 22 universities in five continents in 1990, more than 500 universities signed the Declaration in 2021 (ULSP, n.d.). Another major ESD landmark was the United Nations Framework Convention on Climate Change in 1992. It included an article on 'the development and implementation of educational and public awareness programmes on climate change and its effects' (UN, 1992). Since 2015, ESD has been recognised as 'an integral element of SDG (Sustainable Development Goal) 4 on quality education and a key enabler of all other SDGs' (UNESCO, 2021). The latest ESD global framework for the year 2030 proposes a roadmap for “ESD's 
key role for the achievement of the 17 SDGs and the great individual and societal transformation required to address the urgent sustainability challenges" (UNESCO 2020a, p. 3).

In this context, USD engages the university in its entirety. USD aims at the mutual reinforcement of the university, maintaining its sustainability while playing a creative and crucial role in achieving sustainable development in societies and the world at large. USD encapsulates holistic, transformational, and multi-scalar responsibilities simultaneously with education and training, academic inquiry, empirical application, and cultural development for sustainability. In essence, USD fosters cognitive, social-emotional, and behavioural learning in terms of the content, outcomes and the learning environment for quality lifelong learning. USD today is closely connected with SDG 4.7, which refers to sustainability competence development in the university sector: "to ensure that all learners acquire the knowledge and skills needed to promote sustainable development, including, among others, through Education for Sustainable Development and sustainable lifestyles, human rights, gender equality, promotion of a culture of peace and nonviolence, global citizenship and appreciation of cultural diversity and of culture's contribution to sustainable development" (UN 2015, p. 19).

This paper surveyed the 'landscape' of the university's social responsibilities at multiple scales, illustrating the topographical concept and the mental schemata of the idea of a university in terms of both tradition and innovation. Moreover, the university's intrinsic features of transnationalism and globalism have become increasingly prominent in the context of both rapid technological development and mounting challenges to sustainable development. Therefore, the landscape view of the university's social responsibilities offers "a conceptual framework that can accommodate all these changes, that would help us understand the transformations and inter-connections, inform our thoughts and decisions through a particular comprehensive perspective" (Brock 2016, p. 188).

\section{Editorial Note}

This unpublished article was one of the last written by Colin Brock before he passed away in 2016. Additional writing was added by his former doctoral student, Zhou Zhong (DPhil, Oxon). The Journal of International and Comparative Education (JICE) is publishing this article in memory of Colin, who was instrumental in the formation of the Journal and who served as Chair of the International Advisory Board until his passing.

\section{References}

Bamford, T.W. (1978). The University of Hull: The First Fifty Years. Oxford: Oxford University Press. Boyer, E. (1996). The scholarship of engagement. Bulletin of the American Academy of Arts and Sciences, 49(7), pp. 18-33. DOI: 10.2307/3824459

Brock, C. (2012). Universities, independence, internationalism and integrity. In H.G. Duran \& F. LopezSegrera (Eds). La Internacionalización de la Educación Superior a Nivel Mundial y Regional : Principales Tendencias y Desafios / Compiladores (The Internationalisation of Higher Education Worldwide: Main Trends and Challenges). Bogota: Editorial Planeta Colombiana S.A., pp. 49-62.

Brock, C. (2016). Geography of Education: Scale, Space and Location in the Study of Education. London: Bloomsbury Academic.

Brock, C. \& Alexiadou, N. (2013). Education Around the World: A Comparative Introduction. London/ New York: Bloomsbury Academic.

Cicollela, P. \& Mignaqui, I. (2002). Buenos Aires: Sociospatial impacts of the development of global city functions. In S. Sassen (Ed.) Global Networks/Linked Cities. New York and London: Routledge, pp. 309-326.

Findlay, A.M., King, R., Smith, F.M.. Geddes, A. \& Skeldon, R. (2012). World class? An investigation of globalisation, difference and international student mobility. Transactions of the Institute of British Geographers, 37(1), pp.118-131. DOI: 10.1111/j.1475-5661.2011.00454.x

Fleuret, S. \& Atkinson, S. (2007). Wellbeing, health and geography: A critical review and research agenda. New Zealand Geographer, 63(2), pp.106-118. DOI: 10.1111/j.1745-7939.2007.00093.x 
Fleuret, S. \& Prugneau, J. (2015) Assessing students wellbeing in a spatial dimension. The Geographical Journal, 181 (2), pp.110-120 DOI: 10.1111/geoj.12098

Hopkins, P. (2006). Youth transitions and going to university: the perceptions of students attending a geography summer school access programme. Area, 38(3), pp. 240-247. DOI: 10.1111/j.14754762.2006.00691.x

Hopkins, P. (2011). Towards critical geographies of the university campus: understanding the contested experiences of Muslim students. Transactions of the Institute of British Geographers, 36(1) , pp. 157-169. DOI: 10.1111/j.1475-5661.2010.00407.x

Horton, J. \& Tucker, F. (2014). Disabilities in academic workplaces: experiences of human and physical geographers. Transactions of the Institute of British Geographers, 39(1), pp. 76-89. DOI: $10.1111 / \operatorname{tran} .12009$.

Johnson, L. \& Castleden, H. (2011). Greening the campus without grass: using visual methods to understand and integrate student perspectives in campus landscape development and water sustainability planning. Area, 43(3), pp.353-361. DOI: 10.1111/j.1475-4762.2011.01001.x

Kasperkevic, J. (2014). The Harsh Truth: US Colleges are Businesses, and Student Loans Pay the Bills. Available at: https://www.theguardian.com/money/us-money-blog/2014/oct/07/collegesceos-cooper-union-ivory-tower-tuition-student-loan-debt [Accessed 13 September 2021].

Keohane, R. \& J. S. Nye, J.S. (2000). Introduction. In J.S. Nye \& J. Donahue (Eds.) Governance in a Globalizing World. Washington, D.C: The Brookings Institution Press, pp. 1-14.

Kerr, C. (2001). The Uses of the University ( $5^{\text {th }}$ ed). Cambridge, MA: Harvard University Press.

Mackinder, H. \& Sadler, M.E. (1891). University Extension, Past Present and Future. London, Paris \& Melbourne: Cassell \& Company Limited.

Martin, J. (2006). The Meaning of the $21^{\text {st }}$ Century: A Vital Blueprint for Ensuring our Future. London: Transworld Books/Eden Project.

Maxwell, N. (2013, Oct 25). Reconnecting Economics and Real Life (Letters, the Guardian). Available at: https://www.theguardian.com/education/2013/oct/25/reconnecting-economics-and-reallife [Accessed 24 September 2014].

Morley, D. \& Robbins, K. (1995). Spaces of Identity: Global Media, Electronic Landscape and Cultural Boundaries. London: Routledge.

Riemens, P. \& Lovink, G. (2002). Local networks: Digital city Amsterdam. In S. Sassen (ed.). Global Networks/Linked Cities. New York/London: Routledge, pp. 327-346.

Schiller, N G., Basch, L. \& Blanc, C.S.. (Eds.) (1995) From immigrant to transmigrant: Theorizing transnational migration. Anthropological Quarterly, 68(1), pp.48-63. DOI: 10.2307/3317464

Swain, H. (2016). Wanted: More Universities to Sponsor Free Schools in England. Available at: https:// www.theguardian.com/education/2016/mar/21/wanted-universities-sponsor-free-schoolsengland [Accessed 28 June 2021].

Swain, J., Finkelstein, V., French, S. \& Oliver, M. (1993). (Eds). Disabling Barriers: Enabling Environments. Thousand Oaks, CA: Sage Publications.

Symaco, L.P. \& Brock, C (2016). (Eds). Space, Place and Scale in the Study of Education. London \& New York: Routledge. DOI: 10.4324/9781315652443

Talloires Declaration (1990). The Talloires Declaration 10 Point Action Plan. Association of University Leaders for a Sustainable Future. Available at: http://ulsf.org/talloiresdeclaration [Accessed 13 September 2021].

UNESCO (2020). COVID-19 Educational Disruption and Response. Available at: https://en.unesco. org/news/covid-19-educational-disruption-and-response [Accessed 13 September 2021].

UNESCO (2020a). Education for Sustainable Development: A Roadmap. Paris: UNESCO.

UNESCO (2021). Education for Sustainable Development. Available at: https://en.unesco.org/themes/ education-sustainable-development [Accessed 13 September 2021].

University Leaders for a Sustainable Development (ULSF) (n.d.). Talloires Declaration Signatories List. Available at: http://ulsf.org/96-2/ [Accessed 13 September 2021]. 
United Nations (UN) (1992). The United Nations Framework Convention on Climate Change. Available at: https://unfccc.int/process-and-meetings/the-convention/what-is-the-united-nationsframework-convention-on-climate-change [Accessed 13 September 2021].

United Nations UN (2015). Transforming our World: the 2030 Agenda for Sustainable Development. Available at: https://sdgs.un.org/publications/transforming-our-world-2030-agendasustainable-development-17981 [Accessed 13 September 2021]. 
